\title{
Clinical rearfoot and knee static alignment measurements are not associated with patellofemoral pain syndrome
}

\author{
Medidas clinicas estáticas do retropé e joelho não estão associadas à \\ sindrome da dor patelofemoral
}

Sandra Aliberti', Mariana Souza Xavier Costa², Sílvia Maria Amado João, Anice de Campos Pássaro ${ }^{4}$, Antonio Carlos Arnone ${ }^{5}$, Isabel de Camargo Neves Sacco ${ }^{6}$

\begin{abstract}
I The aim of the present study was to investigate the association between the patellofemoral pain syndrome and the clinical static measurements: the rearfoot and the $\mathrm{Q}$ angles. The design was a cross-sectional, observational, case-control study. We evaluated 77 adults (both genders), 30 participants with patellofemoral pain syndrome, and 47 controls. We measured the rearfoot and $\mathrm{Q}$ angles by photogrammetry. Independent $t$-tests were used to compare outcome continuous measures between groups. Outcome continuous data were also transformed into categorical clinical classifications, in order to verify their statistical association with the dysfunction, and $\chi^{2}$ tests for multiple responses were used. There were no differences between groups for rearfoot angle [mean differences: 0.20 (95\% Cl -1.4-1.8)] and Q angle [mean differences: -0.30 (95\% Cl -3.0-2.4). No associations were found between increased rearfoot valgus [Odds Ratio: 1.29 (95\% Cl 0.51-3.25)], as well as increased Q angle [Odds Ratio: 0.77 (95\% Cl 0.31-1.93)] and the patellofemoral pain syndrome occurrence. Although widely used in clinical practice and theoretically thought, it cannot be affirmed that increased rearfoot valgus and increased $\mathrm{Q}$ angle, when statically measured in relaxed stance, are associated
\end{abstract}

RESUMO I O objetivo deste estudo foi investigar se existe associação entre a síndrome da dor patelofemoral e as medidas clínicas estáticas: os ângulos do retropé e Q. Foi realizado um estudo observacional, transversal, caso-controle, no qual foram avaliados 77 adultos (ambos os sexos), 30 participantes com síndrome da dor patelofemoral e 47 controles. Foram medidos os ângulos do retropé e Q, por meio da fotogrametria. Testes $t$ para amostras independentes foram usados para comparações dos resultados das variáveis contínuas entre os grupos. Os resultados das variáveis contínuas foram transformados em classificações clínicas categóricas, para verificar a associação estatística com a disfunção, e o teste do $\chi^{2}$ para respostas múltiplas também foi utilizado. Não houve diferença entre os grupos para o ângulo do retropé [média da diferença: 0,20 (IC95\% -1,4-1,8)] e ângulo Q [média da diferença: -0,30 (IC95\%-3,0-2,4). Não houve associação entre o ângulo do retropé [Odds Ratio: 1,29 (IC95\% 0,51-3,25)], assim como entre o ângulo Q [Odds Ratio: 0.77 (IC95\% 0,31-1,93)] e a ocorrência da síndrome da dor patelofemoral. Apesar de serem teoricamente justificadas e amplamente utilizadas na prática clínica fisioterapêutica, não pode-se afirmar que as medidas dos ângulos do retropé e Q, quando

\footnotetext{
Estudo desenvolvido no Laboratório de Biomecânica do Movimento e Postura Humana (LaBiMPH) do Departamento de Fisioterapia, Fonoaudiologia e Terapia Ocupacional da Faculdade de Medicina da Universidade de São Paulo (USP) - São Paulo (SP), Brasil. 'Fisioterapeuta; Mestre em Ciências da Reabilitação pelo Departamento de Fisioterapia, Fonoaudiologia e Terapia Ocupacional da Faculdade de Medicina da Universidade de São Paulo (USP) - São Paulo (SP), Brasil.

${ }^{2}$ Fisioterapeuta graduada na USP - São Paulo (SP), Brasil.

3Professora Doutora do Departamento de Fisioterapia, Fonoaudiologia e Terapia Ocupacional da Faculdade de Medicina da USP - São Paulo (SP), Brasil.

${ }^{4}$ Fisioterapeuta; Mestre em Ciências da Reabilitação pelo Departamento de Fisioterapia, Fonoaudiologia e Terapia Ocupacional da Faculdade de Medicina da USP - São Paulo (SP), Brasil.

${ }^{5}$ Médico do Hospital Universitário da USP - São Paulo (SP), Brasil.

${ }^{6}$ Professora Livre-Docente do Departamento de Fisioterapia, Fonoaudiologia e Terapia Ocupacional da Faculdade de Medicina da USP - São Paulo (SP), Brasil.
} 
with patellofemoral pain syndrome (PFPS). These measures may have limited applicability in screening of the PFPS development.

Keywords I patellofemoral pain syndrome; lower extremity; posture mensuradas em posição ortostática, estão associadas com a ocorrência da síndrome da dor patelofemoral. Essas medidas podem ter aplicabilidade limitada na triagem desta disfunção. Descritores I síndrome da dor patelofemoral; extremidade inferior; postura.

\section{INTRODUCTION}

Patellofemoral pain syndrome (PFPS) is one of the most common knee joint dysfunctions, affecting 25\% of the general population and, most commonly, young physically active adult females ${ }^{1,2}$. Despite its high incidence, there is a lack of consensus on its multifactorial etiology $y^{1,3,4}$.

According to Fredericson and Yoon, there is no golden standard test or clinical method for PFPS diagnosis, but there is a set of clinical measurements that confirm the diagnosis of this dysfunction ${ }^{5}$. Although patellofemoral symptoms occur during dynamic conditions, quantitative dynamic evaluation is not always available in daily clinical practice, besides its higher cost. Therefore, static clinical measurements are widely used in PFPS physical examination as this syndrome is supposedly related to lower extremity static misalignment $\mathrm{t}^{5-7}$. The static postural alignment of the rearfoot and the $\mathrm{Q}$ angle are examples of clinical static measurements, which are frequently employed to evaluate individuals during PFPS rehabilitation ${ }^{5,7-9}$.

Theoretically, the static postural alignment of the rearfoot is related to the $\mathrm{Q}$ angle, in such a way that excessive and/or prolonged subtalar pronation could induce medial rotation of the tibia and, therefore, greater femoral medial rotation in a closed kinetic chain ${ }^{10}$. The increased femoral medial rotation would enlarge the Q angle and, consequently, the force vector that pulls the patella laterally would increase the contact forces and pressures on the patellofemoral joint. The higher the $\mathrm{Q}$ angle, the greater the lateral force vector acting to increase the retropatellar pressure, and the greater the risk for developing PFPS ${ }^{6,10,11}$. Some studies did not show a relationship between a higher $Q$ angle and PFPS $^{12,13}$, however a study demonstrated a difference between patients with this knee disorder and asymptomatic individuals ${ }^{14}$.

The static postural alignment of the rearfoot is commonly used to decide whether anti-pronation taping/ortheses should be employed to deal with PFPS individuals that show excessive pronation during the locomotion ${ }^{15,16}$. An increased rearfoot valgus ${ }^{17}$ and increased calcaneal angle ${ }^{7}$ were found during relaxed stance posture in subjects with PFPS, while other authors found no association between rearfoot static posture and incidence of PFPS ${ }^{13,18}$. A systematic review, which evaluated risk factors associated with PFPS, stated that the actual knowledge is still insufficient to confirm the relationship between rearfoot alignment and this dysfunction, therefore, more evidences need to be established $^{19}$.

Although widely recommended in clinical practice and in theoretical thought ${ }^{1,5-7}$, the scientific basis for the association of rearfoot and Q angles with PFPS is still controversial ${ }^{8,9,19}$. Studies with a sample size large enough to allow inferences from the results are necessary to investigate the association between clinical static measures and PFPS. Appropriate measures are important to assist treatment decisions and to help to construct an evidenced-based treatment for the dysfunction.

Therefore, the aim of the present study was to investigate the association between the PFPS and clinical static measurements: the rearfoot and the $\mathrm{Q}$ angles.

\section{METHODS}

\section{Participants}

Seventy-seven adults of both genders (from 18 to 45 years-old) volunteered for this study. Groups were statistically similar (at mean values) for age $(p=0.70)$, height ( $p=0.93)$, and body mass $(p=0.73)$. Baseline characteristics of both groups are presented in Table 1. PFPS participants presented median of 68 (Inter-quartile interval 57 to 74) points in the Lysholm Functional Knee Scale, while the control ones showed median of 98 (Inter-quartile interval 98 to 100) points.

A cross-sectional, observational, case-control study was undertaken. All participants signed an informed 
Table 1. Mean, n (\%) characteristics of each group and mean difference or Odds Ratios and the 95\% confidence interval (95\%Cl) between groups: control and patellofemoral pain syndrome

\begin{tabular}{|c|c|c|c|}
\hline \multirow{2}{*}{ Characteristics } & \multicolumn{2}{|c|}{ Groups } & \multirow{2}{*}{$\begin{array}{c}\text { Difference between groups } \\
\text { PFPS relative to Control }(95 \% \mathrm{Cl})\end{array}$} \\
\hline & PFPS $(n=30)$ & Control $(n=47)$ & \\
\hline Gender, $\mathrm{n}$ female (\%) & $26(87)$ & $42(89)$ & $\mathrm{OR}=0.7(0.1-3.1)$ \\
\hline Age (year), mean (SD) & $30(7)$ & $29(7)$ & $\mathrm{MD}=1.0(-2.2-4.2)$ \\
\hline Height (cm), mean (SD) & $165(9)$ & $164(8)$ & $\mathrm{MD}=1.0(-2.8-4.8)$ \\
\hline Body mass (kg), mean (SD) & $63(11)$ & $59(9)$ & $\mathrm{MD}=4.0(-0.4-8.4)$ \\
\hline Physically active, n (\%) & $12(41)$ & $23(51)$ & $\mathrm{OR}=0.6(0.2-1.7)$ \\
\hline Frequency (days/week), mean (SD) & $3(1)$ & $3(1)$ & $\mathrm{MD}=0.0(-0.4-0.4)$ \\
\hline Duration (minutes), mean (SD) & $67(22)$ & $85(38)$ & $M D=-18.0(-33.0-2.9)$ \\
\hline Time since physically active (year), mean (SD) & $3(4)$ & $5(5)$ & $M D=-2.0(-4.1-0.1)$ \\
\hline VAS (cm), mean (SD) & $1.6(2.3)$ & $0.0(0.0)$ & $\mathrm{MD}=1.6(0.9-2.2)$ \\
\hline
\end{tabular}

SD: standard deviation; PFPS: patellofemoral pain syndrome: Cl: confidence interval; OR: Odds Ratio: MD: mean difference

consent term approved by the Local Ethics Committee (Protocol $\left.n^{\circ} 1237 / 05\right)$. PFPS patients were included if they had pain in the patellofemoral joint area, which arose in at least one of the following situations: resisted contraction of the femoral quadriceps, squatting, prolonged sitting, or descending or ascending stairs ${ }^{4}$. A criterion for inclusion was pain during at least two months ${ }^{4}$. Current pain intensity was individually evaluated using the Visual Analogue Scale; knee function was rated with the Lysholm Functional Knee Scale ${ }^{20,21}$. The intensity of the current pain in the knee region and the functional knee score were evaluated to better characterize the PFPS sample and to ensure that the control group was asymptomatic and functionally healthy. The exclusion criteria for the PFPS group were patellar tendinitis, meniscus and knee ligament injuries, and patellar instability. Exclusion criteria for both groups were: history of knee ligament, tendon or cartilage injury; patellar luxation trauma; previous knee surgery; or lower limb discrepancy equals to or greater than $1 \mathrm{~cm}^{22}$.

As the PFPS is common in physically active individuals, a questionnaire was administered to both groups concerning the frequency, duration, and number of years they had been involved in physical activity. "Physically active" was defined as participation in a minimum of three 30-minute sessions per week of activity requiring a moderate effort, in keeping with established guidelines for physical fitness ${ }^{23}$.

\section{Outcome measures}

Rearfoot and $\mathrm{Q}$ angles were measured by digital photogrammetry ${ }^{24}$, and the participants were photographed on the anterior and posterior frontal plane using a digital camera (Sony; 1600x1200 pixels) positioned at knee height $(\sim 0.7 \mathrm{~m})$ on a tripod $2.4 \mathrm{~m}$ from the platform, parallel to the floor ${ }^{24}$.

The participants were positioned in a relaxed stance position on a wooden platform $(40 \mathrm{~cm}$ long x $40 \mathrm{~cm}$ wide $\mathrm{x} 20 \mathrm{~cm}$ high), which was placed $15 \mathrm{~cm}$ away from the wall with a prumo wire hanging from the ceiling down to the side of the platform to beyond the platform height. To maintain uniform inter-subject positioning, they were told to maintain their feet parallel and an ethylene vinyl acetate rectangle ( $7 \mathrm{~cm}$ wide $\mathrm{x} 30 \mathrm{~cm}$ long) was placed between each subject's feet ${ }^{24}$.

The photometric calculation of the angles was made using a software for postural evaluation (SAPO, version $0.67)^{25}$. Anatomical landmarks were marked with $0.9 \mathrm{~cm}$ self-adhesive tags (Pimaco). Rearfoot angle landmarks were: the midpoint of the posterior lower third of the leg, and the ones of the upper and the lower portion of the calcaneus were marked. Rearfoot angle was formed by the line that comes from the posterior lower third of the leg with that of the lower portion of the calcaneus. The intersection was on the upper portion of calcaneous ${ }^{26}$.

Q angle anatomical landmarks were: anterior superior iliac spine, center of patella, and tibia tuberosity. Q angle was formed by the line that comes from the anterior superior iliac spine and of the tibia tuberosity as they intersect at the center of patella (Figure 1).

All measurements were performed by an experienced physical therapist and, in order to evaluate the intra-rater reliability of the outcome measures, a test-retest was performed with a week of interval and compared by $t$ test for repeated measures and intraclass correlation coefficient. Paired $t$ test did not show differences between the first and second assessments ( $p>0.05)$ for rearfoot and $Q$ angles. Intraclass correlation coefficient showed excellent reliability for the rearfoot angle $(\mathrm{ICC}=0.896)$ and very good for the $\mathrm{Q}$ angle $(\mathrm{ICC}=0.870)^{21}$. 

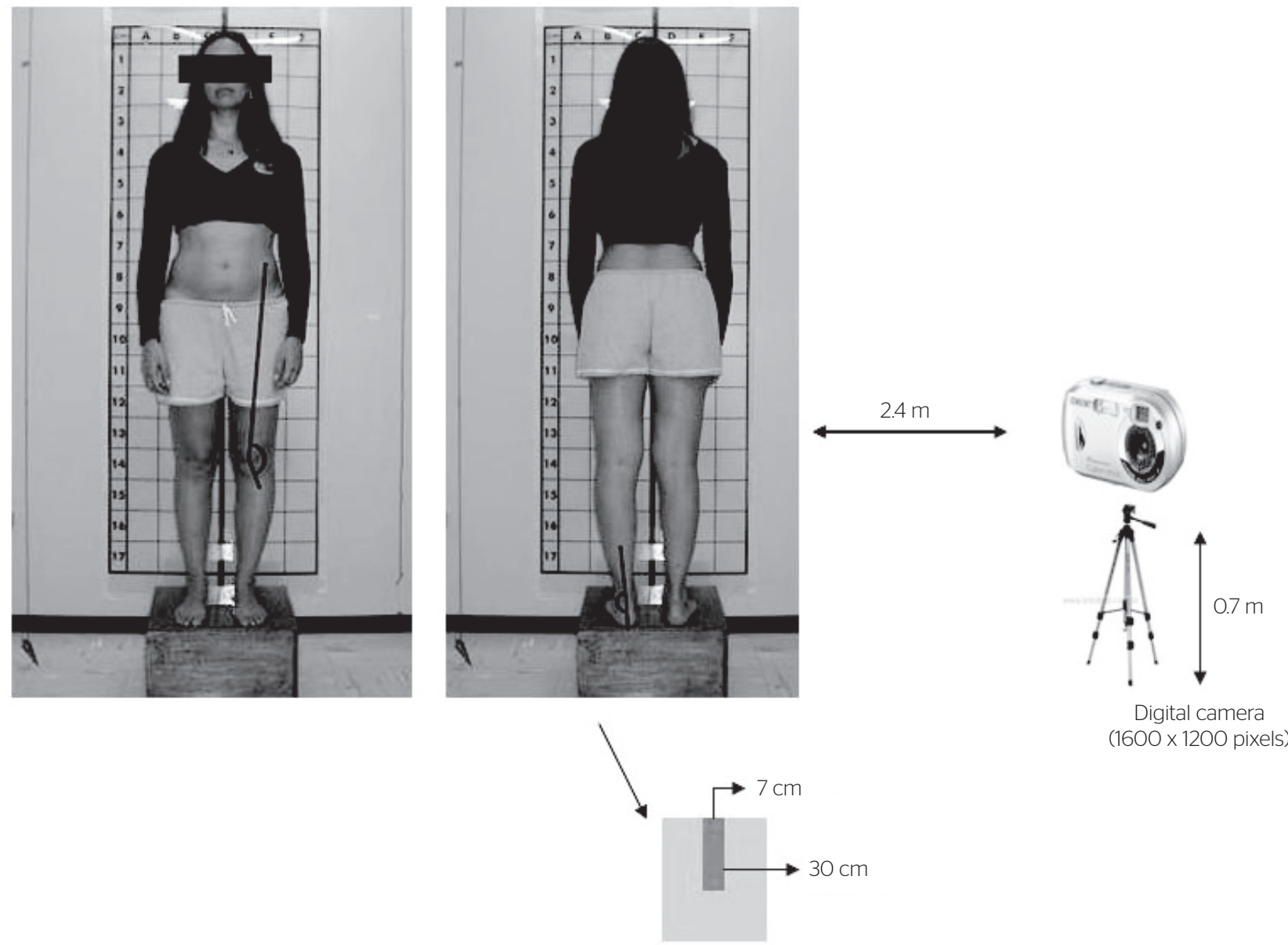

$(1600 \times 1200$ pixels $)$

Figure 1. Data collection setup for rearfoot and $Q$ angles

\section{Data analysis}

The sample size for both groups was calculated based on a proportion of $30 \%$ PFPS development, $80 \%$ of statistical power, and a 5\% significance level ${ }^{2,27}$.

In the PFPS, the leg evaluated was the painful one (unilateral dysfunctions) and the one presenting the greatest pain (bilateral dysfunctions). In the control group, the leg evaluated was randomly selected by lot.

After confirming the normal distribution of all continuous measures (Shapiro-Wilk test), the rearfoot and $\mathrm{Q}$ angles data were compared between groups using independent $t$-tests $(\mathrm{p}<0.05)$. In order to investigate the association between the clinical static measurements and PFPS, we transformed the quantitative continuous measures into qualitative categorical variables using classifications, which are frequently used in clinical practice. The participants from both groups were distributed into clinical categories. Male participants were classified as normal if showed $Q$ angles between $11^{\circ}$ to $15^{\circ}$, diminished lower than $11^{\circ}$ and increased above $15^{\circ 8,28}$. Female participants were classified as normal if presented $Q$ angles between $13^{\circ}$ to $17^{\circ}$, diminished lower than $13^{\circ}$ and increased above $17^{\circ 8,28}$. The participants were classified as varus rearfoot when rearfoot angle was lower than $0^{\circ}$; valgus rearfoot between $0^{\circ}$ to $6^{\circ}$, and increased valgus rearfoot when greater than $6^{016}$.

The qualitative categorical variables were compared between groups using the $\chi^{2}$ test for Multiple Responses to verify association between the clinical variables and PFPS. We adopted a statistical significance level of 0.05 .

\section{RESULTS}

No statistical difference was found between groups for rearfoot $(p=0.30)$ and $Q$ angles $(p=0.62)$, when they were compared as continuous measures (Table 2). When the outcome measures were transformed in categorical data, no association was found between increased rearfoot valgus $(\mathrm{p}=0.67)$ as well as excessive $\mathrm{Q}$ angle $(p=0.49)$ and PFPS occurrence. 
Table 2. Outcome means for each group and mean difference, 95\% confidence interval (95\% Cl) between groups: control and patellofemoral pain syndrome

\begin{tabular}{|c|c|c|c|}
\hline \multirow{2}{*}{ Outcome Measures } & \multirow{2}{*}{ Control $(n=47)$} & \multirow{2}{*}{ PFPS $(n=30)$} & Difference between groups \\
\hline & & & PFPS relative to Control $(95 \% \mathrm{Cl})$ \\
\hline Rearfoot angle (degrees) & $5.3(4)$ & $5.5(3)$ & $0.2(-1.4-1.8)$ \\
\hline Q angle (degrees) & $17.9(6)$ & $17.6(6)$ & $-0.3(-3.0-2.4)$ \\
\hline
\end{tabular}

PFPS: patellofemoral pain syndrome: Cl: confidence interval

Table 3. Number (\%) of participants in each group for each outcome measure and Odds Ratios 95\% confidence interval (95\%Cl) between groups: control and patellofemoral pain syndrome

\begin{tabular}{|c|c|c|c|}
\hline \multirow{2}{*}{ Outcome measures } & \multicolumn{2}{|c|}{ Groups } & \multirow{2}{*}{$\begin{array}{c}\text { Difference between groups } \\
\text { PFPS relative to Control }(95 \% \mathrm{Cl})\end{array}$} \\
\hline & PFPS $(n=30)$ & Control $(n=47)$ & \\
\hline \multicolumn{4}{|l|}{ Rearfoot angle } \\
\hline Varus & $1(3)$ & $3(7)$ & $0.51(0.05-5.10)$ \\
\hline Valgus & $15(50)$ & $25(54)$ & $0.88(0.35-2.20)$ \\
\hline Very valgus & $14(47)$ & $19(39)$ & $1.29(0.51-3.25)$ \\
\hline \multicolumn{4}{|l|}{ Q angle } \\
\hline Diminished & $9(31)$ & $9(20)$ & $1.81(0.62-5.26)$ \\
\hline Normal & $7(24)$ & $13(27)$ & $0.79(0.28-2.30)$ \\
\hline Increased & $14(45)$ & $25(53)$ & 0.77 (0.31-1.93) \\
\hline
\end{tabular}

PFPS: patellofemoral pain syndrome; $\mathrm{Cl}$ : confidence interval

Table 3 shows the number and percentage of participants in each group for each outcome measure and Odds Ratios (95\%CI) between groups. Participants with PFPS presented $8 \%$ more very valgus and $4 \%$ less rearfoot varus than their similar controls. PFPS presented 8\% less increased $Q$ angles and 11\% more diminished $\mathrm{Q}$ angles than their similar controls.

\section{DISCUSSION}

Despite the greater frequency of increased rearfoot valgus among participants with PFPS, there was no significant association between increased rearfoot valgus and excessive $\mathrm{Q}$ angle to the occurrence of PFPS.

Although PFPS showed a greater percentage of increased rearfoot valgus qualitatively, no difference was found between the means of the rearfoot angle presented by both groups, suggesting that there is no relation between rearfoot posture in relaxed stance and the occurrence of PFPS. This finding is in agreement with other studies, which found no difference between rearfoot posture in stance and the occurrence of PFPS $9,13,18$.

Although the reliability of the rearfoot angle found in the present study was excellent, previous reports of reliability have been poor for this measure ${ }^{29}$. This poor general reliability combined with the lack of significance between groups suggests that rearfoot angle may not be the most adequate measure for foot posture determination. Other assessment techniques, like foot posture index, are beginning to be clinically used and may be a more valid alternative method for foot and ankle assessment ${ }^{7}$. The foot posture index involves triplanar evaluation of the foot, instead of rearfoot angle biplanar measurement and this may be an explanation for the better reliability of the former. In addition, further studies that evaluate foot posture in more challenging positions, like unipodal stance or with different knee flexion angles, may provide more information about foot posture and be more specific to predict dynamic function of the foot and ankle complex than relaxed stance evaluation ${ }^{30}$.

There was no difference between the $\mathrm{Q}$ angle means presented by both groups. Emami et al. have found a relation between an increased $Q$ angle and the incidence of PFPS. This study evaluated the $\mathrm{Q}$ angle with a universal goniometer ${ }^{14}$. For this angle, anatomical reference points are distant from each other and the muscle mass and arrangement is such that may hinders the positioning of the goniometer. On the other hand, evaluating the $\mathrm{Q}$ angle using digital photogrammetry improves the reliability of the measure as the anatomical landmarks are marked and the angle is really formed by the intersection of the distant landmarks. This methodological difference may contribute to explain the distinct results between Emami's study results in relation to ours.

The feet of the participants in the present study were positioned parallel at a standardized distance. Although the same inter-participant positioning may have produced some change to the individuals habitual stance and, consequently in our alignment results, our option to position the feet parallel to each other guaranteed 
the standardization of the feet static position and lower variability among participants.

The systematic review organized by Livingston ${ }^{8}$ highlighted that there is still no scientific evidence to support the claim that a greater $\mathrm{Q}$ angle, by itself, can determine the incidence of PFPS. These results have showed that individuals with PFPS presented a surprisingly greater percentage of $\mathrm{Q}$ angles classified as diminished, and a lower percentage of normal $Q$ angles, however these findings were not statistically significant. Thus, the results found in this study do not support the issue of an association between $\mathrm{Q}$ angle and PFPS.

The present study contributes to actual knowledge in PFPS research, since evaluated static measurements that are commonly used in clinical practice in a large sample, using very similar groups, enrich the discussion of the relationship between these measures and the occurrence of PFPS. One of the limitations of this study was that the retrospective design could not differentiate cause and effect results, and consequently conclusions about risk factors could not be affirmed. Besides, categories used to distinguish, when normal alignment ends and misalignment begins, although clinically recognized, do not have their validity established. Nevertheless, the continuous measures did not show differences between groups either, confirming the lack of association between measures and the dysfunction.

Given the multifactorial origin of PFPS, many factors tend to contribute to the development of this dysfunction, consequently it may be difficult to separate and isolate these contributions. Besides that, although this study was not prospective, the lack of association between measures and the occurrence of the dysfunction suggests that they may have limited applicability in screening for risk of PFPS development. It does not mean that these measures cannot assist the categorization of patients into appropriate subgroups, therefore, assisting treatment decisions.

The findings for postural alignment evaluated in this study did not confirm the theory that increased rearfoot valgus and increased $Q$ angle are associated with PFPS in relaxed stance. As this study did not evaluate dynamic alignment, it was not possible to make any association between static and dynamic alignment in this PFPS group. Future studies could attempt to verify this association in PFPS patients.

In clinical practice, performing an inspection of PFPS patients only in relaxed stance may have limited applicability in screening for risk of PFPS development. Future prospective studies may confirm these findings.
Studies that verify the postural alignment in more challenging situations, such as unipodal support or with different knee flexion angles, would contribute to the discussion of the association of postural alignment of the lower limbs and the incidence of PFPS.

\section{CONCLUSIONS}

Although widely used in clinical practice and theoretically thought, it cannot be affirmed that increased rearfoot valgus and increased $Q$ angle when statically measured in relaxed stance are associated with PFPS. These measures may have limited applicability in screening of the development of this syndrome.

\section{ACKNOWLEDGMENTS}

The authors thanks the Fundação de Amparo à Pesquisa do Estado de São Paulo FAPESP (2005/03803-0) for the financial support.

\section{REFERENCES}

1. LaBella C. Patellofemoral pain syndrome: evaluation and treatment. Prim Care. 2004;31:977-1003.

2. Tauton JE, Ryan MB, Clement DB, McKenzie, Lloyd-Smith DR, Zumbo BD. A retrospective case-control analysis of 2002 running injuries. Brit J Sports Med. 2002;36:95.

3. La Botz M. Patellofemoral Syndrome. Phys Sportsmedice. 2004:32:22-9.

4. Davis IR, Powers CM. Patellofemoral pain syndrome: Proximal, Distal e Local Factors. An International Research Retreat. J Orthop Sports Phys Ther. 2010;40:A1-48.

5. Fredericson M, Yoon K. Physical examination and patellofemoral pain syndrome. Am J Phys Med Rehabil. 2006;85:234-43.

6. Powers $\mathrm{CM}$. The influence of altered lower-extremity kinematics on patellofemoral joint dysfunction: a theoretical perspective. J Orthop Sports Phys Ther. 2003;33:639-46

7. Barton CJ, Bonanno D, Levinger P, Menz HB. Foot and ankle characteristics in patellofemoral pain syndrome: a case-control and reliability study. J Orthop Sports Phys Ther. 2010;40:286-96.

8. Livingston LA. The quadriceps angle: a review of the literature. J Orthop Sports Phys Ther. 1998;28:105-9.

9. Livingston LA, Mandigo JL. Bilateral rearfoot asymmetry and anterior knee pain syndrome. J Orthop Sports Phys Ther. 2003;33:48-55. 
10. Tibério D. The effect of excessive subtalar joint pronation on patellofemoral mechanics:a theoretical model. J Orthop Sports Phys Ther. 1987;9:160-5.

11. Smith TO, Hunt NJ, Donell ST. The reliability and validity of the Q angle: a systematic review. Knee Surg Sports Traumatol Arthrosc. 2008;16:1068-79.

12. Caylor D, Fites R, Worrell TW. The relationship between quadriceps angle and anterior knee pain syndrome. J Orthop Sports Phys Ther. 1993;17:11-6.

13. Thomee R, Renstrom P, Karlsson J, Grimby G. Patellofemoral pain syndrome in young women. I. A clinical analysis of alignment, pain parameters, common symptoms and functional activity level. Scand J Med Sci Sports. 1995;5:237-44.

14. Emami MJ, Ghahramani MH, Abdinejad F, Namazi H. Q angle: an invaluable parameter for evaluation of anterior knee pain. Arch Iran Med. 2007:10:24-6.

15. Cheung RT, Ng GY, Chen BF. Association of footwear with patellofemoral pain syndrome in runners. Sports Med. 2006;36:199-205.

16. Eng JJ, Pierrynowski MR. Evaluation of soft foot orthotics in the treatment of patellofemoral pain syndrome. Phys Ther. 1993;73:62-8.

17. Levinger P, Gilleard W. An evaluation of the Rearfoot Posture in individuals with patellofemoral pain syndrome. J Sports Sci Med. 2004:3:8-14.

18. Messier SP, Davis SE, Curl WW, Lowery RB, Pack RJ. Etiologic factors associated with patellofemoral pain in runners. Med Sci Sports Exerc. 1991;23:1008-15.

19. Waryasz GR, McDermott AY. Patellofemoral pain syndrome (PFPS): a systematic review of anatomy and potential risk factors. Dyn Med. 2008;7:9.

20. Lysholm J, Gillquist J. Evaluation of knee ligament surgery results with special emphasis on use of a scoring scale. Am J Sports Med. 1982:10:150-4.
21. Wahlund K, List T, Dworkin SF. Temporomandibular disorders in children and adolescents: reliability of a questionnaire, clinical examination, and diagnosis. J Orofac Pain. 1998:12:42-51.

22. Aliberti S, Costa MXS, Passaro AC, Arnone AC, Sacco ICN. Medial contact and smaller plantar loads characterize individuals with patellofemoral pain syndrome during stair descent. Phys Ther in Sport. 2010;11:30-4.

23. Shephard RJ. Limits to the measurement of habitual physical activity by questionnaires. Br J Sports Med. 2003;37:197-206.

24. Sacco I, Aliberti S, Queiroz B, Pripas D, Kieling I, Kimura A, et al. Reliability of photogrammetry in relation to goniometry for postural lower limb assessment. Rev Bras Fisioter. 2007;11:411-7.

25. Ferreira EAG, Duarte M, Burke TN, Maldonado EP, Marques AP. Postural Assessment Software: Validation and Reliability. Clinics. 2010;65:675-81.

26. Kernozek T W, Gerr NL. Quadriceps Angle and Rearfoot Motion: Relationships in Walking. Arch Phys Med Rehabil. 1993;74:407-10.

27. Breslow NE, Day NE. Statistical methods in cancer research. The analysis of case-control studies. Lyon: IARC Scientific Publications; 1980.

28. Livingston LA, Mandigo JL. Bilateral within-subject $Q$ angle asymmetry in young adult females and males. Biomed Sci Instrum. 1997;33:112-7.

29. Iunes DH, Castro FA, Salgado HS, Moura IC, Oliveira AS, BevilaquaGrossi D. Intra and inter-examiner reliability and method repeatability of postural evaluation via photogrammetry. Braz J Physical Ther. 2005:9:327-34.

30. Levinger P, Gilleard WL, Sprogis K. Frontal plane motion of the rearfoot during a one-leg squat in individuals with patellofemoral pain syndrome. J Am Podiatr Med. 2006;96:96-101. 